\title{
MINERAL ADDITIVES AND CACTUS ADDED TO ENRICHED ANIMAL MANURE AS COMPOST FOR ENHANCING CHICKPEA AGRICULTURAL EFFICIENCY
}

\author{
ELfADIL, S. ${ }^{*}$ - JAOUAD, A. - MAHROUZ, M. - BOUChDOUG, M. \\ Team of Search, Innovation, Sustainable Development, Green Chemistry and Expertises, \\ Semlalia Faculty of Science, Cadi Ayyad University, 24000 Marrakech, Morocco \\ (phone: +212-5-2443-4649; fax: +212-5-2443-6769) \\ *Corresponding author \\ e-mail: elfadilsaida@gmail.com; phone: +212-6-3887-5242; fax: +212-5-2443-6769 \\ (Received $17^{\text {th }}$ Jun 2019; accepted $28^{\text {th }}$ Aug 2019)
}

\begin{abstract}
In this research we studied the effect of compost including phosphate flotation waste, phosphogypsum and cactus on chickpea (Cicer arietinum L.) plant growth and yield for 4 months under greenhouse systems in morocco. Chickpea development presented elevated variability. Phosphate flotation waste, contrary to the phosphogypsum, had positive effects on chickpea productivity; significant increase in biomass yield was demonstrated under phosphate flotation waste treatment $(38.16 \%)$ and combination of phosphate flotation waste and cactus (48.87\%). Phosphate flotation waste improved chickpea yield parameters and its effect was even more significant while adding cactus. Cactus might be a good material for enhancing the absorbance of nutrients by plants. When the phosphate flotation wastecactus combination was optimal, supplementary parameters productivity was registered in certain situations. Furthermore, this research was the first to establish that the mixture including phosphate flotation waste, manure and cactus could not only enhance plant yield and growth but further assume for long-term agricultural productivity and right soil fertility.
\end{abstract}

Keywords: phosphate flotation waste, phosphogypsum, cactus, physicochemical characterization of treatments, soil physicochemical properties, chickpea yield

\section{Introduction}

Intensive cultivation and the failure to implement effective soil conservation practices for chickpea (Cicer arietinum L.) to meet the global demand has damaged the natural supply, and soil fertility and nutrients. Looking forward to obtaining a good fertility of soil and optimal yield, cultivated lands require proper management and recycling of organic wastes on land to protect agricultural soils.

In the last years, ammonium nitrate has been the best-known origin of nitrogen $(\mathrm{N})$ on behalf of soil amendment in crop fertilization. Though, relative to else Nitrogen origin, ammonium nitrate is fairly luxurious and its production is probably to decrease during the decades to come (Wang et al., 2016). Under such scene, animal manure is getting more increasingly employed as an $\mathrm{N}$ origin nutriment for crop agriculture. To the same effect, in various countries, phosphorous $(\mathrm{P})$ is the major growth restricting soil fertility; phosphate amendments have a critical role in pacing agricultural activity to shift human food productivity to the levels observed today. Though Yi et al. (2017) emphasize the utilizable deposits of phosphate are very restricted.

Further, evidencing the rooted dependency of food production on soil nutrients such $\mathrm{P}$, in an alarming way (Cordel et al., 2009) prognostic a worldwide revolution in $\mathrm{P}$ production to arise by 2030 . Yet the amendment production acknowledges the turn down in quantity and quality of international reserves along with the increasing costs of mining, meeting out and caring of $\mathrm{P}$ (Childers et al., 2011). Besides to these problems, 
there is a rising appreciation of the environmental expenses of the present system of food production. Unfortunate nutrient running of soils and sustained use of synthetic amendments have had harmful effects on soil fertility (Ke et al., 2017). To maintain food industry in excess of time and to provide effective utilization of accessible resources with maximum competence, it is crucial that enhanced methods and techniques for completing crop productivities are considered and agreed (Ganesapillai et al., 2015).

To this fact, Phosphate Flotation Waste (PFW) generated from beneficiation of Moroccan phosphate rocks is of great concern in composting as a low-grade phosphate rock (Elfadil et al, 2016). Phosphate rock, and for consequence PFW have been acknowledged as an alternating source for P nutrient. In Morocco, it is estimated that there are approximately 260 million tons of phosphate rock deposits and that material will present a shameful source of phosphate fertilizer for crop production (Tanner, 1961). Unfortunately, phosphor is not readily available to the plants in soils with a $\mathrm{pH}>5.5-6.0$. Because of this, extension services are reluctant to recommend it and farmers are hesitant to utilize phosphate rock directly. furthermore, It was reported by Luo et al. (2013) and $\mathrm{Hu}$ et al. (2007) that phosphogypsum, the main by-product of phosphoric acid production, might be effective in composting in the sense where he can reducing $\mathrm{NH}_{4}$ emissions during by increasing $\mathrm{SO}_{4}{ }^{2-}$ content of the compost, and Luo et al. (2013) indicated that the addition of phosphogypsum at a rate of $10 \%$ of total compost mixture (dry weight) decreased $\mathrm{NH}_{3}$ emissions significantly during pig manure composting.

Besides, cactus has been recommended as a bio-adsorbent because of it high retention (Sakr et al., 2015); so can it considered as a good quality-low charge substituted fertilizer that can offer a well-off source of amendment to improve agricultural productivity?

This research presents an original approach to increase soil fertility by the combined application including Phosphate flotation waste PFW, phosphogypsum (Pg), cactus and animal manure. While the use of Phosphate rock enriched composts has been the question of current studies (Moharana and Biswas, 2016), there have been awfully no information on the application of PFW, Pg and cactus in soils. Therefore, in the present study, the application of Phosphate flotation waste, phosphogypsum and cactus enriched animal manure on the plant development reply parameters of Chickpea (Cicer arietinum L.) was inquired.

\section{Materials and methods}

\section{Sampling and sample pretreatment}

Animal manure was obtained from forty farms in Chichaoua city with good-balanced regimes. Fresh manure samples were composed in air-tight comprising and refrigerated less than $20^{\circ} \mathrm{C}$ to keep away from ammonia volatilization (Ke et al., 2017). The results of this study are summarized in Table 1 .

Phosphate flotation waste and phosphogypsum tailings with $43.8 \% \mathrm{Ca}_{3} \mathrm{PO}_{4}(20.05 \%$ $\mathrm{P}_{2} \mathrm{O}_{5}$ ) were obtained from industrial mines of Khouribga. Commercial grade Triple Super-Phosphate (TSP) with $45 \% \quad \mathrm{P}_{2} \mathrm{O}_{5}$ was obtained from Moroccan Institute for Agronomic Research in Settat city (INRA Settat). Composts are prepared with various mixtures of these raw materials;

Prior to the study, TSP was crushed and screened to size less than $2.5 \mathrm{~mm}$. 
the details of the treatments is: T1: the control (soil without addition); T2: soil and manure compost; T3: soil and compost of manure and PFW (6:4); T4: soil and compost of manure and phosphogypsum (6:4); T5: soil and compost of manure, PFW and cactus age under 6 mouth) (6:3:1); T6: soil and compost of manure, PFW and cactus (age above 6 mouth) (6:3:1); T7: soil and TSP. Three doses were applied of each treatment: $0.06 \mathrm{t} / \mathrm{ha}, 0.6 \mathrm{t} / \mathrm{ha}$ and $6 \mathrm{t} / \mathrm{ha}$.

The experiments were carried out in the laboratory with an average room temperature of $25 \pm 3{ }^{\circ} \mathrm{C}$ and relative humidity as $60 \%$.

Table 1. Nutritional statues of soil, compost, and soil compost mixes at the begining of the trial

\begin{tabular}{|c|c|c|c|c|c|c|}
\hline Treatments & $\begin{array}{l}\text { Total N (mg.g }{ }^{-1} \\
\text { of dry matter) }\end{array}$ & $\begin{array}{l}\text { Avail. N ( } \mu g^{-1}{ }^{-1} \\
\text { of dry matter) }\end{array}$ & $\mathbf{P}_{2} \mathrm{O}_{5}(\%)$ & $\begin{array}{l}\text { Avail. } P\left(\mu g g^{-1}\right. \\
\text { of dry matter) }\end{array}$ & $\mathrm{K}_{2} \mathrm{O}(\%)$ & $\begin{array}{l}\text { Avail. K ( } \mu g \cdot g^{-1} \\
\text { of dry matter) }\end{array}$ \\
\hline $\mathrm{T} 1$ & 3.33 & 832.62 & 1.23 & 729 & 8.03 & 856 \\
\hline $\mathrm{T} 21$ & 4.26 & 951.00 & 5.84 & 5843.23 & 9.12 & 1525.00 \\
\hline $\mathrm{T} 22$ & 5.32 & 1112.23 & 6.23 & 6421.21 & 10.42 & 1952.00 \\
\hline $\mathrm{T} 23$ & 6.53 & 1541.22 & 6.69 & 7011.55 & 11.23 & 2214.00 \\
\hline $\mathrm{T} 31$ & 6.26 & 953.00 & 7.84 & 5845.23 & 11.12 & 1527.00 \\
\hline $\mathrm{T} 32$ & 6.65 & 1113.56 & 7.56 & 6422.54 & 11.75 & 1953.33 \\
\hline $\mathrm{T} 33$ & 8.68 & 1542.55 & 8.02 & 7012.88 & 12.56 & 2215.33 \\
\hline $\mathrm{T} 41$ & 6.88 & 953.62 & 8.46 & 5845.85 & 11.74 & 1527.62 \\
\hline $\mathrm{T} 42$ & 7.20 & 1114.11 & 8.11 & 6423.09 & 12.30 & 1953.88 \\
\hline $\mathrm{T} 43$ & 9.57 & 1544.26 & 9.73 & 7014.59 & 14.27 & 2217.04 \\
\hline $\mathrm{T} 51$ & 5.04 & 951.78 & 6.62 & 5844.01 & 9.90 & 1525.78 \\
\hline T52 & 5.73 & 1112.64 & 6.64 & 6421.62 & 10.83 & 1952.41 \\
\hline T53 & 7.27 & 1541.96 & 7.43 & 7012.29 & 11.97 & 2214.74 \\
\hline $\mathrm{T} 61$ & 2.98 & 949.72 & 4.56 & 5841.95 & 7.84 & 1523.72 \\
\hline T62 & 3.85 & 1110.76 & 4.76 & 6419.74 & 8.95 & 1950.53 \\
\hline $\mathrm{T} 63$ & 6.12 & 1540.81 & 6.28 & 7011.14 & 10.82 & 2213.59 \\
\hline $\mathrm{T} 71$ & 8.59 & 955.33 & 10.17 & 5847.56 & 13.45 & 1529.33 \\
\hline $\mathrm{T} 72$ & 11.32 & 1118.23 & 12.23 & 6427.21 & 16.42 & 1958.00 \\
\hline $\mathrm{T} 73$ & 13.35 & 1548.04 & 13.51 & 7018.37 & 18.05 & 2216.48 \\
\hline
\end{tabular}

T1: the control; T21: soil and $0.06 \mathrm{t} / \mathrm{ha}$ of manure compost; T22: soil and $0.6 \mathrm{t} / \mathrm{ha}$ of manure compost; T23: soil and $6 \mathrm{t} / \mathrm{ha}$ of manure compost; T3: soil and compost of manure and PFW; T4: soil and compost of manure and phosphogypsum; T5: soil and compost of manure, PFW and cactus (age under 6 mouth); T6: soil and compost of manure, PFW and cactus (age above 6 mouth); T7: soil and TSP

\section{Experimental mode}

A greenhouse experiment with chickpea plants was conducted from the beginning of September to the beginning of January 2015 (140 days) at the National institute of agronomic research (INRA) site located in Settat (Morocco), located at an altitude of about 400 m, Lambert coordinates X: 292.413 and Y: 263.664.

The site is located in the semi-arid bioclimatic stage with an average rainfall of between 300 and $350 \mathrm{~mm}$ concentrated between the months of October and May and a very temperate average temperature varying between $5{ }^{\circ} \mathrm{C}$ during the months December and January to $38{ }^{\circ} \mathrm{C}$ during the summer. Compound soil samples were obtained from a profundity of $0.2 \mathrm{~m}$ from the surface and screened throughout a $6 \mathrm{~mm}$ hole. The soil 
used was red loam with $4.33 \%$ gravel, $92.84 \%$ sand and $2.83 \%$ fine; this soil was used for its proper properties and its impermeability. Trays $(0.44 \times 0.32 \times 0.14 \mathrm{~m})$ were packed with $4 \mathrm{~kg}$ of air-dried soil and studied with 3 replications. Trays were approved as plant divide arrays. Every array included plant replicates of the soil treatments, on a network including 3 rows by 18 columns of trays. Inside every array, the soil treatments were owed depending on a randomized complete block (RCB) plan, consequently this group of plant pots inside every line incorporated one repeat. 6 composts, prepared from phosphate flotation waste, phosphogypsum, animal manure and cactus, were additional to the respective trays 2 days previous to kernel planting and sprayed to ensure proper dissolution of composts in the soil. Trays were divided into plant slots and 3 seeds were planted in both pots at a profundity of $30 \mathrm{~mm}$ in greenhouse (Fig. 1). After germination, plants were watered down to 3 per slot for all the plates. All plants were periodically watered with de-ionized water through the research period. Upon maturity (about 4 months following planting the seeds) all plants were reaped and the plants phisicomorphological characteristics and biomass yield were identified. Preliminary pot experiment was set up with a set of 7 treatments.

For the seven treatments except the control, 3 doses are adopted with 3 replications:

- A dose of $0.06 \mathrm{t} / \mathrm{ha}$ of compost was selected for fertilization so $2 \mathrm{~g}$ of each compost. This dose was applied to the individual plots at the level of each treatment.

- A dose of $0.6 \mathrm{t} / \mathrm{ha}$ so $20 \mathrm{~g}$ of each compost.

- A maximum dose of $6 \mathrm{t} / \mathrm{ha}$ so $200 \mathrm{~g}$ of each compost.

During the experimental period, homogeneous irrigation (50 1 for each plot) without chemical fertilizing was carried out regularly every five days with tap water using a drip system.

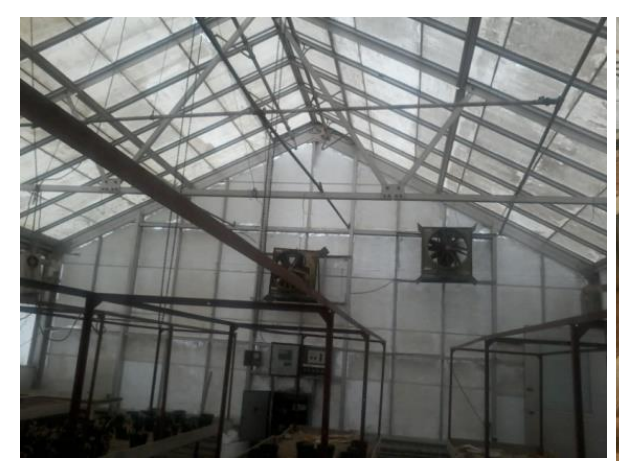

$\mathbf{a}$

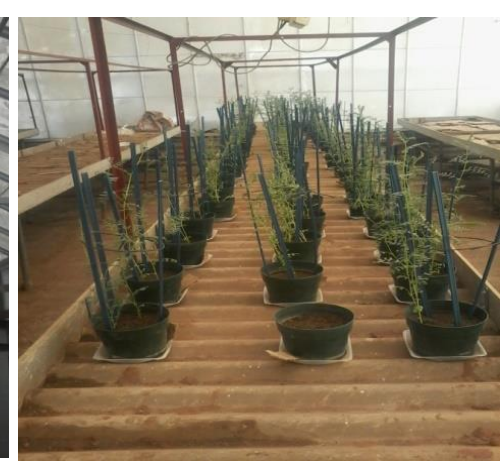

$\mathbf{b}$

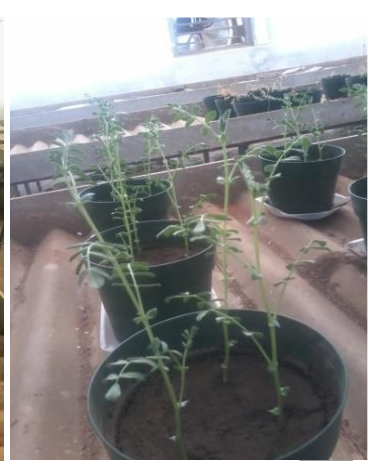

C

Figure 1. $(a, b)$ Layout of pot and greenhouse experiment. (c) Nodules on treated chickpea plants from pot experiment

\section{Plant physicochemical analysis}

The unamended soil was included for its primary characteristics (Table 2). Postharvesting, oven dried at $40{ }^{\circ} \mathrm{C}$, plants was grinded at $2 \mathrm{~mm}$ screen. All the samples were characterize for total phosphorus, total nitrogen, total potassium and transferable cations ( $\mathrm{P}, \mathrm{K}$, and $\mathrm{N}$ ); $\mathrm{pH}$ was measured in $0.01 \mathrm{M} \mathrm{CaCl}_{2}$ (1: 5) (Simpson, 1988). Total phosphorus and nitrogen were determined by means of the Dumas incineration method 
at $900{ }^{\circ} \mathrm{C}$ with an oxygen run rate of $125 \mathrm{ml} \mathrm{min}^{-1} . \mathrm{P}, \mathrm{N}$ and $\mathrm{K}$ transferable were measured using absorption method. Exchangeable cations $\mathrm{P}$ (Olsenet al., 1960), K and $\mathrm{N}$ were measured using absorption method.

The contents of the air party of chickpea in fertilizing elements, in trace elements and in heavy metals, are determined by the Inductively Coupled Plasma Atomic Emission Spectroscopy (ICP-AES) to the laboratory Reminex of the company Managem of Marrakesh Morocco.

Table 2. Effect of manure and different rates of compost amendments alone and in combination on growth promotion of chickpea plants compared to mineral fertilizer TSP after $140 \mathrm{~d}$

\begin{tabular}{c|c|c|c|c|c|c}
\hline Treatment & $\begin{array}{c}\text { Number of } \\
\text { pods }\end{array}$ & $\begin{array}{c}\text { Weight of } \\
\text { pods }(\mathbf{g})\end{array}$ & $\begin{array}{c}\text { Number of } \\
\text { seeds }\end{array}$ & $\begin{array}{c}\text { Weight of } \\
\text { seeds (g) }\end{array}$ & $\begin{array}{c}\text { Yield plant } \\
\text { biomass (g) }\end{array}$ & $\begin{array}{c}\text { Root length } \\
\text { (cm) }\end{array}$ \\
\hline $\mathrm{T} 3$ & $15.00 \mathrm{a}(2.70)$ & $2.70 \mathrm{abc}(0.40)$ & $6.67 \mathrm{a}(4.27)$ & $1.97 \mathrm{ab}(0.11)$ & $8.58 \mathrm{~b}(0.44)$ & $16 \mathrm{a}(1.17)$ \\
$\mathrm{T} 5$ & $8.14 \mathrm{abc}(0.89)$ & $3.61 \mathrm{a}(0.04)$ & $6.86 \mathrm{a}(3.18)$ & $2.73 \mathrm{a}(0.03)$ & $8.17 \mathrm{~b}(0.76)$ & $13.86 \mathrm{~b}(0.67)$ \\
$\mathrm{T} 6$ & $8.20 \mathrm{abc}(0.64)$ & $2.10 \mathrm{abc}(0.08)$ & $4.80 \mathrm{abc}(1.10)$ & $1.48 \mathrm{ab}(0.02)$ & $11.24 \mathrm{ab}(1.00)$ & $17.70 \mathrm{ab}(1.64)$ \\
$\mathrm{T} 4$ & $5.00 \mathrm{bc}(1.00)$ & $0.96 \mathrm{c}(0.03)$ & $2.33 \mathrm{c}(1.80)$ & $0.64 \mathrm{~b}(0.07)$ & $5.20 \mathrm{~b}(0.39)$ & $16.78 \mathrm{ab}(1.32)$ \\
$\mathrm{T} 6$ & $7.40 \mathrm{bc}(0.51)$ & $3.05 \mathrm{ab}(0.08)$ & $6.00 \mathrm{ab}(2.00)$ & $2.21 \mathrm{ab}(0.08)$ & $16.68 \mathrm{a}(1.90)$ & $17.80 \mathrm{ab}(2.38)$ \\
$\mathrm{T} 2$ & $11.00 \mathrm{ab}(1.54)$ & $2.79 \mathrm{abc}(0.17)$ & $5.67 \mathrm{abc}(3.04)$ & $1.98 \mathrm{ab}(0.08)$ & $10.46 \mathrm{ab}(1.01)$ & $20.33 \mathrm{a}(1.67)$ \\
$\mathrm{T} 1$ & $3.00 \mathrm{c}(0.11)$ & $1.09 \mathrm{c}(0.02)$ & $2.00 \mathrm{c}(0.23)$ & $0.53 \mathrm{~b}(0.01)$ & $8.24 \mathrm{~b}(0.67)$ & $17.17 \mathrm{ab}(1.75)$ \\
\hline
\end{tabular}

T1: the control (soil without addition); T2: soil and manure compost; T3: soil and compost of manure and PFW; T4: soil and compost of manure and phosphogypsum; T5: soil and compost of manure, PFW and cactus (age under 6 mouth); T6: soil and compost of manure, PFW and cactus (age above 6 mouth); T7: soil and TSP. Data are given as mean of three replicates (standard deviation)

\section{Physiological analysis}

The harvest of pods and plants was started on 140-day-old plants and the following characteristics were recorded for each collected plant: number and weight of pods, number and weight of seeds.

The roots of each plant were washed carefully and their lengths were determined.

\section{Statistical analysis}

The plant development data was originated to track normal distribution screening homogeneity of variances with correlation analysis. The data was statistically analyzed throughout SAS at a level of significance set at $\mathrm{P}<0.05$ using Anova followed by Dancun as a post-hoc test.

\section{Results and discussion}

\section{Soil, compost, and potting mixture analysis}

Nutrient condition of the soil, Composts and potting mixtures of soil and compost is exposed in Table 1. Among the macrofertilizers, availability of $\mathrm{P}$ was the uppermost, tracking by $\mathrm{K}$ and then $\mathrm{N}$ in the Composts, while soil presented upper concentrations of available $\mathrm{N}$, tracking by $\mathrm{K}$, and afterward $\mathrm{P}$. Comparison of the results showed that the compost contained higher amounts of all macronutrients analyzed compared with the control. Upon substitution of soil with Composts, availability of macronutrients like N, 
$\mathrm{P}$, and $\mathrm{K}$ in potting mixtures increased significantly with increasing proportions of compost substitutions (Table 1).

\section{Chickpea biomass production}

The treatments studied and the responsiveness of plant growth characteristics have been presented (Tables 2 and 3). Intended for all treatments, the efficiency of PFW enriched animal manure was originated to be improved than that of the control (Table 2; $\mathrm{p}<0.05)$. Relative to seeds weight, following tendency was showed for the control and 6 different treatments with all the three doses: $\mathrm{T} 5>\mathrm{T} 7>\mathrm{T} 2>\mathrm{T} 3>\mathrm{T} 6>\mathrm{T} 4>\mathrm{T} 1$ (Fig. 2d). A parallel tendency was showed for pods weight with the control, cactus 2 and phosphogypsum providing the lowly value. Relative to total plant biomass a different pattern was apparent: $\mathrm{T} 7>\mathrm{T} 6>\mathrm{T} 2>\mathrm{T} 3>\mathrm{T} 1>\mathrm{T} 5>\mathrm{T} 4$ (Fig. 2c); significant augment in biomass yield was confirmed in treatments T3 $(38.16 \%)$ and T5 $(28.87 \%)$ (Fig. 2a). However, enhancement of plant root length was most pronounced under T62 $\left(0.06 \mathrm{t} \mathrm{ha}^{-1}\right.$ of T2) (Fig. 2b).

Table 3. Correlation matrix between quality parameters of PFW enriched composts

\begin{tabular}{c|c|c|c|c|c|c}
\hline Temperature & $\mathbf{p H}$ & $\mathbf{K}_{\mathbf{2}} \mathbf{O}$ & $\mathbf{K}_{\text {ech }}$ & $\mathbf{N i t r a t e}$ & $\mathbf{P}_{\mathbf{2}} \mathbf{O}_{\mathbf{5}}$ & $\mathbf{P}_{\text {assi }}$ \\
\hline $\mathrm{pH}$ & \multirow{2}{*}{1.00000} & $\begin{array}{c}0.19944^{*} \\
0.5343\end{array}$ & $\begin{array}{c}0.78039 \\
0.0027\end{array}$ & $\begin{array}{c}0.58550 \\
0.0455\end{array}$ & $\begin{array}{c}0.86056 \\
0.0003\end{array}$ & $\begin{array}{c}0.78785 \\
0.0023\end{array}$ \\
\hline \multirow{2}{*}{$\mathrm{K}_{2} \mathrm{O}$} & & 1.00000 & $\begin{array}{c}0.97254^{*} \\
0.8227\end{array}$ & $\begin{array}{c}0.31061^{*} \\
0.6258\end{array}$ & $\begin{array}{c}-0.28143^{*} \\
0.8755\end{array}$ & $\begin{array}{c}-0.05033^{*} \\
0.8766\end{array}$ \\
\hline \multirow{2}{*}{$\mathrm{K}_{\text {ech }}$} & & & 1.00000 & $\begin{array}{c}-0.94788 \\
<.0001\end{array}$ & $\begin{array}{c}-0.31589^{*} \\
0.3172\end{array}$ & $\begin{array}{c}-0.49368^{*} \\
0.1029\end{array}$ \\
\hline Nitrate & & & & 1.00000 & $\begin{array}{c}0.57492^{*} \\
0.0505\end{array}$ & $\begin{array}{c}0.59263 \\
0.0423\end{array}$ \\
\hline $\mathrm{P}_{2} \mathrm{O}_{5}$ & & & & & 1.00000 & $\begin{array}{c}0.95821 \\
<.0001\end{array}$ \\
\hline \multirow{2}{*}{$\mathrm{P}_{\text {assi }}$} & & & & & & 1.00000 \\
\hline
\end{tabular}

*Correlation is significant at the 0.05 level

With compost input of $0.6 \mathrm{t}_{2} \mathrm{O}_{5} \mathrm{ha}^{-1}$ to the soil, a different tendency was presented with rising compost dose adding. The majority of plant growth responsiveness parameters responded positively as $\mathrm{P}$ addition was augmented to $0.6 \mathrm{t} \mathrm{ha}^{-1}$. Additional supplementation with $\mathrm{P}$ had resulting to decrease growth characteristics relatively to previous treatments while the results were still improved than that of the control. Hosseinpur et al. (2011) indicated comparable results for chickpea where they recommended that, rising application of inorganic $\mathrm{P}$ fertilizer further than $40 \mathrm{~kg} \mathrm{P} \mathrm{ha}^{-1}$ reduce leguminous $\mathrm{P}$-fixation. They also recommend that for the benefits of starter $\mathrm{P}$ to be performed and the yield of chickpea to be improved, levels as significant as $0.6 \mathrm{~kg} \mathrm{~N}$ $\mathrm{ha}^{-1}$ could be necessary for optimizing the yields. While PFW input of $0.6 \mathrm{t} \mathrm{P}_{2} \mathrm{O}_{5} \mathrm{ha}^{-1}$ yields positive results relatively to the control for all treatments, supplementary resource-use performance might be ensured throughout the optimal $\mathrm{P}$ additive identify. This study reports $0.6 \mathrm{t} \mathrm{ha}^{-1}$ as a positive level of chickpea agriculture. For instance, allowing for pod number as the responsiveness parameter; treatment $\mathrm{T} 5\left(6 \mathrm{t} \mathrm{P} \mathrm{ha}^{-1}\right)$ 
relative to $\mathrm{T} 5\left(0.6 \mathrm{t} \mathrm{P} \mathrm{ha}^{-1}\right)$ showed that supplementary $\mathrm{P}$ addition results in reduced number of pods (T5 is $86 \%$ of T4) nevertheless still considerably higher than the control $\mathrm{T} 1$ ( $\mathrm{p}<0.05)($ Table 2). Parallel result and watching of tendency for $\mathrm{P}$ addition to soils cultivating chickpeas was indicated by many authors (Saini et al., 2004; Wei et al., 2015; Iyer et al., 2017).

On the other hand, mineral amendments have larger agronomic competence for the reason that their elements are available and effortlessly captivated by plants. This would be due to the rapid release of nutrients to soils and plants, as demonstrated by Abdelhamid et al. (2004) in a study comparing the economic profitability of inorganic and organic fertilizers in faba bean (Vicia faba L.). On the other hand, the dose of $0.6 \mathrm{t}$ $\mathrm{ha}^{-1}$ of manure compost is much more efficient than 0.06 or $6 \mathrm{t} \mathrm{ha}^{-1}$. These results (Table 2; Fig. 2) show the value and necessity of using low doses in case of low availability of organic materials. This confirms the studies of Ukem (2010) who advocate the use of small quantities of compost in vegetable and soybean crops.

\section{Effect of cactus addition on chickpea biomass production}

Cactus with PFW resulting in enhanced chickpea growth as well as dry matter increase could be awarded to mechanisms as the creation of indoleacetic acid along with dissolving of unsolvable phosphate alongside with uncharacterized characteristics making fertilizers more willingly available for plant uptake. Cactus facilitates enhanced mineral nutrient absorption as a result of varying the physiological rank along with morphological characteristic of inoculated roots, and therefore promotion of root growth is considered as one of the major markers by which the beneficial effect of plant growth promotion by cactus is measured. Increased root length in the seed treatments may thus be influenced by cactus (Table 2; Figs. 2 and 3).

Increase in growth as well as dry matter build-up in chickpea plants in the combined a of high compost use substitution as well as cactus and manure was better than the amount of their individual applications, possibly as an effect of the synergistic input of both parameters in the enhancement of the physico-chemical characteristics and nutritional factors. The benefits of this combination are more likely to synchronize nutrient release from the compost and soil with plant nutrition demand as well as involvement of cactus and manure modulation of the plant root architecture for more efficient acquisition of soil nutrients. In this study, cactus with manure improved the tested parameters of growth due to their synergistic effect. This supposed that manure substitution separately was powerless to provide the plants with enough quantities of willingly available fertilizers as well as enhancement of plant growth unlike the combinations.

\section{Effect of toxicity of the novel composts on chickpea plant}

Heavy metals are regarded as trace elements due to their existence in low contents (in ppm) in different eco-systems (Meharg, 2011). Their bio-assimilates is affected by various physical parameters (temperature, adsorption...), chemical parameters (thermodynamic equilibrium, complexation kinetics, lipid solubility...) (Hamelink, 1994) and biological parameters (species characteristics, biochemical/physiological adaptation...) (Martin, 1995).

The contents in cadmium and lead were low for all the treatments $(<2 \mathrm{ppm}$ and $<26$ ppm respectively); also the concentrations of nickel and chromium were weak 
and stay below the international standards: AFNOR norme. The copper and zinc concentrations of the various plants were superior with regard to the no amended treatment especially for the treatment which contains of the small cactus, what can be to explain by the strong adsorption of the cactus of the zinc and the copper.

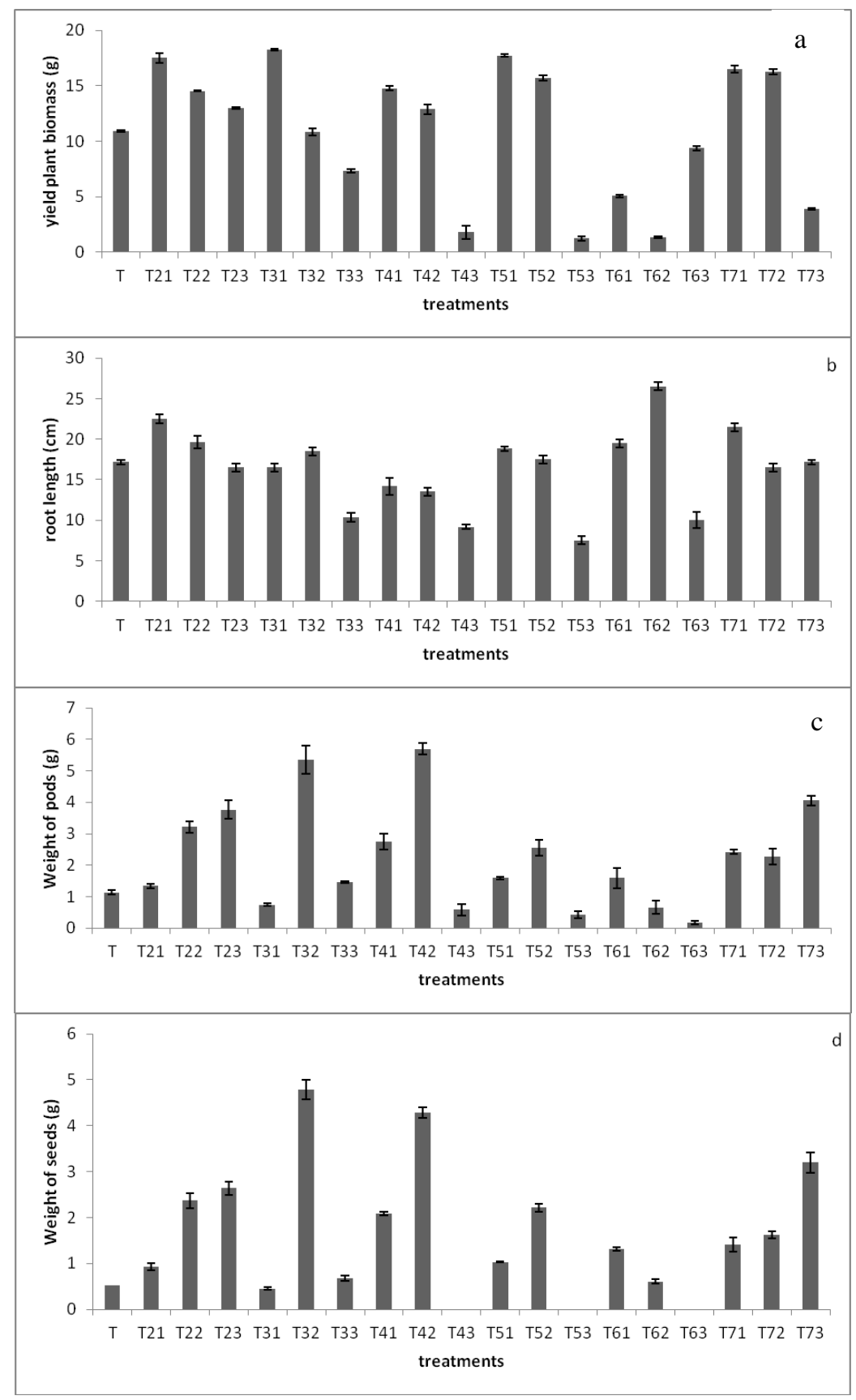

Figure 2. Influence of enriched composts on (a) yield plant biomass; (b) root length; (c) Weight of pods; (d) Weight of seeds per plant in the various treatments. T1: the control; T21: soil and 0.06 t/ha of manure compost; T22: soil and $0.6 \mathrm{t} / \mathrm{ha}$ of manure compost; T23: soil and $6 \mathrm{t} / \mathrm{ha}$ of manure compost; T3: soil and compost of manure and PFW; T4: soil and compost of manure and phosphogypsum; T5: soil and compost of manure, PFW and cactus (age under 6 mouth);

T6: soil and compost of manure, PFW and cactus (age above 6 mouth); T7: soil and TSP. Modulation values are back transformed from loge means. LSD5\% value is therefore the least significant ratio (LSR5\%) 


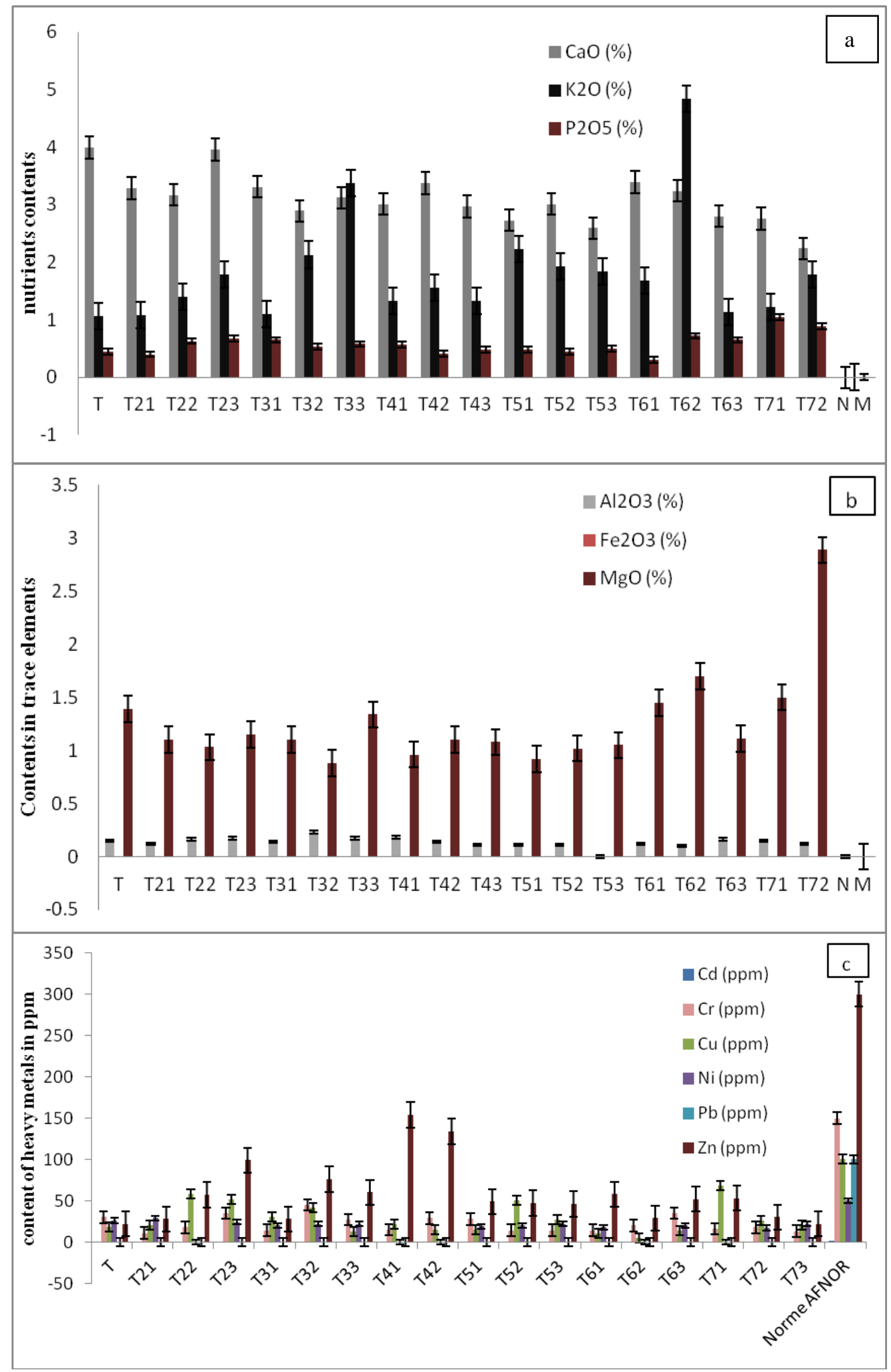

Figure 3. Contents in nutrients $(a)$, traces elements $(b)$ and elements metallic tracks $(c)$ in chickpea plant in the various treatments. T1: the control; T21: soil and 0.06 t/ha of manure compost; T22: soil and 0.6 t/ha of manure compost; T23: soil and 6 t/ha of manure compost;

T3: soil and compost of manure and PFW; T4: soil and compost of manure and phosphogypsum; T5: soil and compost of manure, PFW and cactus (age under 6 mouth); T6: soil and compost of manure, PFW and cactus (age above 6 mouth); T7: soil and TSP 


\section{Conclusion}

This research confirmed an approach to fertilize plants via the combined application of wastes resources; PFW, phosphogypsum, animal manure and cactus. That confirmed the elevated performance observed in reactivates parameters of Cicer arietinum as the product of treatment $\mathrm{T} 4\left(\mathrm{PFW}\right.$ at $0.6 \mathrm{t} \mathrm{P}_{2} \mathrm{O}_{5} \mathrm{ha}^{-1}$ and cactus at $0.6 \mathrm{~kg} \mathrm{P} \mathrm{ha}^{-1}$ ). The addition of PFW and phosphogypsum fitting nature of Cicer arietinum, chemical analyses of soil subsequent the harvest presented an augmentation in total soil phosphorus; cactus have clear beneficial effect to increased supply of Phosphorus, changes in the growth rate of chickpea and absorption of heavy metals by plants.

Unfortunately, some of the studied treatments exacerbate certain problems with mineral additives, especially regarding heavy metals accumulations. For this reason, research is in progress to ameliorate the physicochemical conditions for using these additives improvers and also to investigate the links between heavy metals accumulation in cultivated soils, the physical and hydraulic properties, and soil productivity.

Acknowledgments. The authors would like to thank anonymous reviewer for his useful comments and the high ministry of education of morocco. Mr A. Bousetta (Reminex Unit - Managem Morocco), is thanked for the help concerning ICP analysis. The authors would like Mr E. El Mzouri the Director of INRA Settat Morocco.

\section{REFERENCES}

[1] Abdelhamid, M., Horiuchi, T., Oba, S. (2004): Composting of rice straw with oilseed rape cake and poultry manure and its effects on faba bean (Vicia faba L.) growth and soil $\begin{array}{lllll}\text { properties. } & - & \text { Bioresource } & \text { Technology } & \text { 93: }\end{array}$ http://dx.doi:10.1016/j.biortech.2003.10.012.

[2] Childers, D., Corman, J., Edwards, M., Elser, J. (2011): Sustainability challenges of phosphorus and food: solutions from closing the human phosphorus cycle. - BioScience 61: 117-124. http://dx.doi:10.1525/bio.2011.61.2.6.

[3] Cordell, D., Drangert, J., White, S. (2009): The story of phosphorus: global food security and food for thought. - Global Environmental Change 19: 292-305. http://dx.doi:10.1016/j.gloenvcha.2008.10.009.

[4] Elfadil, S., Bouchdoug, M., Jaouad, A. (2016): Physico-chemical characterization of phospahtes flotation waste and its potential us as a composting amendment. - IJIR 2(5): 71-77.

[5] Ganesapillai, M., Simha, P., Zabaniotou, A. (2015): Closed-loop fertility cycle: realizing sustainability in sanitation and agricultural production through the design and implementation of nutrient recovery systems for human urine. - Sustainable Production and Consumption 4: 36-46. http://dx.doi:10.1016/j.spc.2015.08.004.

[6] Hamelink, J. (1994): Bioavailability. - Lewis Publishers, Boca Raton.

[7] Hosseinpur, A., Kiani, S., Halvaei, M. (2011): Impact of municipal compost on soil phosphorus availability and mineral phosphorus fractions in some calcareous soils. Environmental Earth Sciences 67: 91-96. http://dx.doi:10.1007/s12665-011-1482-1.

[8] Hu, T., Zeng, G., Huang, D., Yu, H., Jiang, X., Ai, I. F., Huang, G. (2007): Use of potassium dihydrogen phosphate and sawdust as adsorbents of ammoniacal nitrogen in aerobic composting process. - Journal of Hazardous Materials 141: 736-744. http://dx.doi:10.1016/j.jhazmat.2006.07.027. 
[9] Iyer, B., Rajput, M., Rajkumar, S. (2017): Effect of succinate on phosphate solubilization in nitrogen fixing bacteria harbouring chick pea and their effect on plant growth. Microbiological Research 202: 43-50. http://dx.doi:10.1016/j.micres.2017.05.005.

[10] Ke, J., Xing, X., Li, G., Ding, Y., Dou, F., Wang, S., Liu, Z., Tang, S., Ding, C., Chen, L. (2017): Effects of different controlled-release nitrogen fertilisers on ammonia volatilisation, nitrogen use efficiency and yield of blanket-seedling machine-transplanted rice. - Field Crops Research 205: 147-156. http://dx.doi:10.1016/j.fcr.2016.12.027.

[11] Luo, Y., Li, G., Luo, W., Schuchardt, F., Jiang, T., Xu, D. (2013): Effect of phosphogypsum and dicyandiamide as additives on NH3, N2O and $\mathrm{CH} 4$ emissions during composting. - Journal of Environmental Sciences 25: 1338-1345. http://dx.doi:10.1016/s1001-0742(12)60126-0.

[12] Martin, M. (1995): Plants as biomonitors: indicators for heavy metals in the terrestrial environment VCH. $\quad-\quad$ Phytochemical Analysis 6: 112-112. http://dx.doi:10.1002/pca.2800060209.

[13] Meharg, A. (2011): Trace elements in soils and plants. 4th edition. By A. Kabata-Pendias. - Experimental Agriculture 47: 739-739. http://dx.doi:10.1017/s0014479711000743.

[14] Moharana, P., Biswas, D. (2016): Assessment of maturity indices of rock phosphate enriched composts using variable crop residues. - Bioresource Technology 222: 1-13. http://dx.doi:10.1016/j.biortech.2016.09.097.

[15] Olsen, S., Watanabe, F., Cole, C. (1960): Effect of sodium bicarbonate on the solubility of phosphorus in calcareous soils. - Soil Science 89: 288-291. http://dx.doi:10.1097/00010694-196005000-00010.

[16] Sakr, F., Sennaoui, A., Elouardi, M., Tamimi, M., Assabbane, A. (2015): Étude de l'adsorption du Bleu de Méthylène sur un biomatériau à base de Cactus (Adsorption study of Methylene Blue on biomaterial using cactus). - J. Mater. Environ. Sci. 6(2): 397406. https://www.jmaterenvironsci.com/Document/vol6/.../48-JMES-1115-2014Sakr.pdf.

[17] Saini, V., Bhandari, S., Tarafdar, J. (2004): Comparison of crop yield, soil microbial C, N and $\mathrm{P}, \mathrm{N}$-fixation, nodulation and mycorrhizal infection in inoculated and non-inoculated sorghum and chickpea crops. - Field Crops Research 89: 39-47. http://dx.doi:10.1016/j.fcr.2004.01.013.

[18] Simpson, K. (1988): Plant analysis. Edited by D. J. Reuter and J. B. Robinson. Melbourne: Inkata Press. - Experimental Agriculture 24: 129-129. http://dx.doi:10.1017/s0014479700015775.

[19] Tanner, C. (1961): Book review: fertiliser report and statistics, 1959. - Outlook on Agriculture 3: 98-98. http://dx.doi:10.1177/003072706100300211.

[20] Ukem, B. (2010): Effect of a complementary application of Algifol nutrient solution and npk on growth, flowering and yield of tomato in a northern guinea savanna soil of Nigeria. - Global Journal of Agricultural Sciences 8. http://dx.doi:10.4314/gjass.v8i2.51892.

[21] Wang, Y., Dong, H., Zhu, Z., Li, L., Zhou, T., Jiang, B., Xin, H. (2016): CH4, NH3, N2O and $\mathrm{NO}$ emissions from stored biogas digester effluent of pig manure at different temperatures. - Agriculture, Ecosystems \& Environment 217: 1-12. http://dx.doi:10.1016/j.agee.2015.10.020.

[22] Wei, Y., Zhao, Y., Xi, B., Wei, Z., Li, X., Cao, Z. (2015): Changes in phosphorus fractions during organic wastes composting from different sources. - Bioresource Technology 189: 349-356. http://dx.doi:10.1016/j.biortech.2015.04.031.

[23] Yi, K., Wang, D., QiYang, Li, X., Chen, H., Sun, J., An, H., Wang, L., Deng, Y., Liu, J., Zeng, G. (2017): Effect of ciprofloxacin on biological nitrogen and phosphorus removal from wastewater. - Science of the Total Environment 605-606: 368-375. http://dx.doi:10.1016/j.scitotenv.2017.06.215. 